\title{
Device Malfunctions and Complications Associated with Benign Prostatic Hyperplasia Surgery: Review of the Manufacturer and User Facility Device Experience Database
}

\author{
Neel H. Patel, MD, ${ }^{1}$ Nikil Uppaluri, MD,' Michael lorga, MD, ${ }^{1}$ Ariel Schulman, MD, ${ }^{2}$ \\ Jonathan B. Bloom, MD, ${ }^{3}$ John Phillips, MD, Sean Fullerton, MD, ${ }^{1}$ Sensuke Konno, PhD, \\ Muhammad Choudhury, MD, and Majid Eshghi, MD ${ }^{1}$
}

\begin{abstract}
Introduction and Objectives: Multiple surgical therapies for benign prostatic hyperplasia (BPH) have been developed to decrease complications and increase provider efficiency. We investigated contemporary BPH treatment device-related adverse events by searching a publicly available database.

Materials and Methods: The Manufacturer and User Facility Device Experience (MAUDE) database was queried for contemporary BPH treatments. All devices were evaluated for malfunction, patient complications, and manufacturer review. The MAUDE adverse event classification system was used to standardize complications. Univariate analysis was performed to identify associations between BPH devices and adverse events. Results: A total of 2567 reports were identified: transurethral resection of the prostate (TURP) 197 (7.67\%), holmium laser enucleation of the prostate (HoLEP) 39 (1.52\%), GreenLight ${ }^{\mathrm{TM}} 2315(90.2 \%)$, and UroLift ${ }^{\circledR} 16$ $(0.62 \%)$. The most common deviations for each modality included cutting loop detachment during TURP 116 (58.9\%), morcellator dysfunction for HoLEP 23 (58.9\%), tip fracture/detachment for GreenLight (68.8\%), and failure to deploy during UroLift $10(62.5 \%)$. Only $18(0.7 \%)$ patients required medical/surgical management (MAUDE II-IV) due to a device complication. No significant relationship was seen between each modality and complications; however, morcellator use $(27.8 \%)$ was observed in higher grade complications. Manufacturer review occurred in $61.7 \%$ of cases, with $41.3 \%$ of reviewed cases finding the operator the cause of the malfunction. Conclusion: Each BPH modality investigated had minimal patient harm with over $99 \%$ of patients experiencing no complication after device malfunction. Of note, great care should be taken with morcellator use during HoLEP as it had the greatest number of MAUDE II to IV complications among all devices. Manufacturer review revealed that over $40 \%$ of cases were due to misuse by the user. Therefore, urologists should select the modalities they are most familiar with to decrease patient harm and prevent device malfunctions.
\end{abstract}

Keywords: prostatic hyperplasia, minimally invasive surgical procedures, equipment and supplies

\section{Introduction}

B enign Prostatic Hyperplasia (BPH) is a histological diagnosis associated with unregulated proliferation of connective tissue, smooth muscle, and glandular epithelium within the prostatic transition zone. ${ }^{1}$ The prevalence of $\mathrm{BPH}$ is $8 \%, 50 \%$, and $80 \%$ in the fourth, sixth, and ninth decades of life, respectively. ${ }^{2}$ Affected patients can experience a combination of irritative and obstructive lower urinary tract symptoms, with prolonged obstruction leading to acute urinary retention, urinary tract infections, bladder calculi, and renal insufficiency. ${ }^{3}$ With a combination of increased life expectancy and a large aging population, BPH management is and will remain a common urological disorder.

Treatment options include medical management with alphablockers or 5-alpha reductase inhibitors. Surgical management has improved significantly with time and availability of new technology. Transurethral resection of the prostate (TURP) is

\footnotetext{
${ }^{1}$ Department of Urology, New York Medical College, Valhalla, New York.

${ }^{2}$ Department of Urology, Maimonides Medical Center, Brooklyn, New York.

${ }^{3}$ Urologic Oncology Branch, National Cancer Institute, National Institutes of Health, Bethesda, Maryland.
} 
still considered the gold standard to which other modalities are compared. Introduction of bipolar technology and the decreased concern for post-TURP syndrome have allowed for increased resection times compared with monopolar technology. Other modalities, which include use of a laser, include photoselective vaporization of the prostate with GreenLight ${ }^{\mathrm{TM}}$ XPS and holmium laser enucleation of the prostate (HoLEP). More recently, the UroLift ${ }^{\circledR}$ technology has been introduced, which allows for placement of implants in the lateral lobes of the prostate, allowing for retraction of tissue without ablation or excision. Promising technology includes prostatic ablation by hydrodissection and convective energy transfer with the use of steam. ${ }^{4}$ While studies focus on the efficacy of the modality with regard to improvement in symptom score and flow rate, studies describing the safety of devices and their malfunctions are limited.

The Manufacturer and User Facility Device Experience (MAUDE) database is a Food and Drug Administration (FDA)-maintained public database that contains mandatory and voluntary medical device reports. The reports provide insight on suspected device-associated deaths, serious injuries, and malfunctions. This voluntary self-reporting database has a large potential for underreporting of events. However, due to its anonymous nature, the MAUDE database allows for reporting of any perceived unwanted events and allows room for practitioner awareness and improvement in patient safety.

Gupta et al. examined device complications of robotic surgery and proposed a novel classification system that was used to standardize complications from the MAUDE database. ${ }^{5}$ Modeled off the Clavien-Dindo classification system, this MAUDE classification was adapted for device-related adverse events and each event was divided into four categories: level I (none/mild) - with no harm occurring to the patient, level II (moderate) - with harm to the patient requiring minor intervention, level III (severe) - with harm to the patient requiring major intervention, and level IV (lifethreatening/death). The utility of this complication system was later applied to endourologic procedures with application in percutaneous nephrolithotomy device malfunctions. ${ }^{6}$

In this study, we reviewed contemporary BPH management devices and technologies for which adverse events were reported to the FDA-maintained MAUDE database by applying the previously described MAUDE classification system to compare device-associated complication rates and patient outcomes.

\section{Materials and Methods}

Using the phrase "Transurethral resection of the prostate (TURP), Holmium Laser Enucleation of the Prostate
(HoLEP), GreenLight ${ }^{\mathrm{TM}}$, and UroLift ${ }^{\circledR}$," we queried the MAUDE database from January 2015 to October 2017 for any device-related malfunction or deviation and complication that may have occurred due to device use. We also obtained data regarding the occupation of the informant, whether the device was reviewed by the manufacturer, and the source of the defect after review. Duplicate cases and cases with incomplete data were excluded. Device-related complications were then used to categorize these data into the previously described MAUDE classification system.

\section{Statistical analysis}

Fisher's exact test and univariate logistic regression were performed to compare adverse outcomes that resulted in none or mild adverse events (level I) with those that resulted in moderate or severe events (levels II-IV). A separate subset analysis was performed of outcomes without GreenLight cases to control for lack of standardized reporting and disproportional numbers. Odds ratios (OR) with confidence intervals $(95 \% \mathrm{CI})$ were reported, with $p$-values less than 0.05 considered statistically significant. Statistics were calculated using Stata, version 12 (College Station, TX).

\section{Results}

A total of 2567 medical device reports were reviewed from January 2015 to October 2017 for BPH-related treatments. Our query of the MAUDE database resulted in 197 TURP (7.67\%), 39 HoLEP (1.52\%), 2315 GreenLight (90.2\%), and 16 UroLift $(0.62 \%)$ reported events. Table 1 lists the overall device complications and associated MAUDE complication level, with 2549 (99.3\%) cases as level I or mild complications, 9 cases $(0.35 \%)$ requiring minor intervention for a moderate complication (level II), 8 cases $(0.31 \%)$ requiring aggressive intervention for a severe complication (level III), and 1 case of a life-threatening event (level IV) due to sepsis. No deaths were recorded within this time period.

Table 2 describes the malfunctions for each BPH treatment modality. The most common malfunctions for TURP were detachment of the cutting loop (58.9\%) and resectoscope (23.3\%). There were 16 reported cases (8.1\%) of an electrical fire due to cable malfunction. Issues with HoLEP include morcellator dysfunction $(58.9 \%)$ and detachment of the laser fiber $(33.3 \%)$ and endoscope $(7.7 \%)$. GreenLight ${ }^{\mathrm{TM}}$ malfunctions include fracture or detachment of the tip (68.8\%) and end firing of the laser $(29.4 \%)$. Use of UroLift ${ }^{\circledR}$ was associated with failure to deploy $(62.5 \%)$ and detachment or fixation of the needle (37.5\%).

Univariate logistic regression was performed of all devices across all treatment modalities, comparing cases with no

Table 1. Manufacturer and User Facility Device Experience Classification System Highlighting Most Common Types of Device Malfunctions

\begin{tabular}{lccccc}
\hline Device & Overall & TURP & HoLEP & UroLift $^{\circledR}$ & GreenLight $^{\mathrm{T}}$ \\
\hline MAUDE I & $2549(99.3 \%)$ & $188(95.4 \%)$ & $34(87.2 \%)$ & $14(87.5 \%)$ & $2313(99.9 \%)$ \\
MAUDE II & $9(0.35 \%)$ & $5(2.5 \%)$ & $1(2.6 \%)$ & $1(6.3 \%)$ & $2(0.1 \%)$ \\
MAUDE III & $8(0.31 \%)$ & $4(2.0 \%)$ & $3(7.7 \%)$ & $1(6.3 \%)$ & $0(0 \%)$ \\
MAUDE IV & $1(0 \%)$ & $0(0 \%)$ & $1(2.6 \%)$ & $0(0 \%)$ & $0(0 \%)$ \\
\hline
\end{tabular}

HoLEP $=$ holmium laser enucleation of the prostate; MAUDE $=$ Manufacturer and User Facility Device Experience; TURP $=$ transurethral resection of the prostate. 
Table 2. Most Common Device Malfunctions as Reported in the MAUDE Database

\begin{tabular}{llll}
\hline TURP $\mathrm{n}=197(7.6 \%)$ & HoLEP $\mathrm{n}=39(1.5 \%)$ & GreenLight $^{\mathrm{TM}} \mathrm{n}=2315(90.2 \%)$ & UroLift $^{\circledR} \mathrm{n}=16(0.6 \%)$ \\
\hline Malfunction & & & \\
Cutting loop detachment & Laser fiber detachment & Glass cap/tip fracture or detachment & Failure to deploy \\
$116(58.9 \%)$ & $13(33.3 \%)$ & $1592(68.8 \%)$ & $10(62.5 \%)$ \\
Resectoscope detachment & Morcellator dysfunction & End firing & Needle detachment/stuck \\
$46(23.3 \%)$ & $23(58.9 \%)$ & $681(29.4 \%)$ & $6(37.5 \%)$ \\
Cable electrical fire & Laser scope detachment & Fiber body breakage & - \\
$16(8.1 \%)$ & $3(7.7 \%)$ & $27(1.2 \%)$ & - \\
Cable detachment & & Failure to fire & \\
$5(2.5 \%)$ & & $15(0.6 \%)$ & \\
\hline
\end{tabular}

harm (level I) with those with moderate or severe harm (levels II-IV). As seen in Table 3, GreenLight ${ }^{\mathrm{TM}}$ showed an improved safety profile compared with other device modalities (OR 0.01, CI: $0.003-0.056, p<0.001)$. Absolute risk reduction (ARR) was $47 \%$ using GreenLight ${ }^{\mathrm{TM}}$. Due to the nonstandardized nature of reporting in the MAUDE database, GreenLight ${ }^{\mathrm{TM}}$ cases were reported at a much higher number than other treatment modalities and were analyzed separately.

In Table 4, the analysis excluding GreenLight ${ }^{\mathrm{TM}}$ therapy showed that TURP (OR 0.457, CI: 0.169-1.384) was least likely to be associated with a significant grade II-IV complication compared with HoLEP (OR 1.27, CI: 0.378-4.142) and UroLift ${ }^{\circledR}$ (OR: 2.26, CI: 0.526-8.480); however, this was not statistically significant. Overall, $99.3 \%$ of all BPH treatments were not related with significant harm.

A total of 18 unique complications were reported, with the most common complications across all the device classes being 7 conversions to open $(38.9 \%), 3$ cutaneous burns (16.7\%), 2 urethral injuries (11.1\%), 2 bladder perforations (11.1\%), 2 hemorrhages (11.1\%), 1 second procedure $(5.5 \%)$, and 1 intensive care unit admission $(5.5 \%)$ as seen in Table 5. Morcellator dysfunction with HoLEP $(27.8 \%)$ was associated with the most significant complications resulting in three conversions to open, one hemorrhage, and one ICU admission. While over $50 \%$ of these defects were attributed to manufacturing defects, the rest were not evaluated. TURP resulted in the remaining cutaneous burns, conversions to open, and urethral injury, but the device was not evaluated in $75 \%$ of cases or the cause was found to be unknown. Extraperitoneal bladder perforation was seen with GreenLight ${ }^{\mathrm{TM}}$ and a second procedure/hemorrhage with UroLift ${ }^{\circledR}$, all related to misuse by the user. Furthermore, the breakdown across all device classes within each modality is listed in Table 6. Each device is stratified by its association with its MAUDE level (I-IV) and harm that occurred to the patient.

Medical device reports were generated by physicians (26.3\%), nurses $(24.7 \%)$, risk managers $(2.9 \%)$, and user facilities/other $(46.1 \%)$. The malfunctioning device was evaluated by the manufacturer in $61.7 \%$ of cases and in $41.3 \%$ of such inquiries; malfunction was determined to be due to misuse of the device by the operator. No association was seen between specific devices and any particular manufacturers for TURP or HoLEP devices.

\section{Discussion}

This study examined four commonly used and contemporary BPH treatment modalities: TURP, HoLEP, GreenLight ${ }^{\mathrm{TM}}$, and UroLift ${ }^{\circledR}$. The majority $(99.3 \%)$ of device complications seen with these modalities were found to have no significant patient-related harm or complications. Furthermore, $41.3 \%$ of malfunctions evaluated by the manufacturer were due to misuse by the operator.

With a high and increasing prevalence with age, BPH treatment remains a common urological problem. Development of various tools and gadgets to treat lower urinary tract symptoms while maintaining sexual function has been an area of great interest. Laser techniques such as HoLEP and GreenLight $^{\mathrm{TM}}$ have been used, which provide equivalent outcomes for large prostatic adenomas $(>60 \mathrm{~g})$, while HoLEP can be efficacious in large glands $(>150 \mathrm{~g}){ }^{7}$ Compared with TURP, HoLEP is associated with lower blood loss, lower transfusion rates, and a shorter hospital stay, but complicated by longer operative time and postoperative dysuria. ${ }^{8}$ Simi- $^{-}$ larly, GreenLight ${ }^{\mathrm{TM}}$ remains a safe and cost-effective technique with minimal blood loss as it can be used in patients on anticoagulation and also be performed as an ambulatory

Table 3. Association of Benign Prostatic Hyperplasia Treatment Modalities and the Risk of Device Malfunction

\begin{tabular}{|c|c|c|c|c|c|}
\hline & MAUDE I & MAUDE II-IV & Odds ratio & $C I$ & $\mathrm{p}$ \\
\hline TURP & 188 & 9 & 12.56 & $4.92-32.01$ & $<0.001$ \\
\hline HoLEP & 34 & 5 & 28.45 & $9.61-84.24$ & $<0.001$ \\
\hline UroLift $^{\circledR}$ & 14 & 2 & 22.63 & $4.75-107.82$ & $<0.001$ \\
\hline GreenLight $^{\mathrm{TM}}$ & 2313 & 2 & 0.01 & $0.003-0.056$ & $<0.001$ \\
\hline Total & 2549 & 18 & - & - & - \\
\hline
\end{tabular}

$\mathrm{CI}=$ confidence interval. 
Table 4. Subset Analysis of Benign Prostatic Hyperplasia Treatment Modalities and Risk of Device Malfunction

\begin{tabular}{lccccc}
\hline & MAUDE I & MAUDE II-IV & Odds ratio & CI & $\mathrm{p}$ \\
\hline TURP & 188 & 9 & 0.457 & $0.169-1.384$ & 0.319 \\
HoLEP & 34 & 5 & 1.27 & $0.378-4.142$ & 0.722 \\
UroLift $^{\circledR}$ & 14 & 2 & 2.26 & $0.526-8.480$ & 0.269 \\
Total & 236 & 16 & - & - & - \\
\hline
\end{tabular}

procedure. ${ }^{9}$ Development of further minimally invasive treatment techniques and devices has given way to prostatic urethral lift with UroLift, allowing for another treatment option where BPH can be surgically managed in an office setting. Although TURP remains superior to UroLift ${ }^{\circledR}$ with regard to the International Prostate Symptom Score (IPSS) and urinary flow rates $\left(Q_{\max }\right)$, both show improvements in IPSS, $Q_{\max }$, and quality-of-life scores, with UroLift showing superior postoperative recovery and ejaculatory function. ${ }^{10}$ With various treatment modalities available, modern-day

Table 5. Patient Complications Substratified by Device Malfunction and Manufacturer Review

\begin{tabular}{|c|c|c|c|c|}
\hline $\begin{array}{l}\text { Device } \\
\text { class }\end{array}$ & Device & Complication & Cause & $\begin{array}{l}\text { Manufacturer } \\
\text { review }\end{array}$ \\
\hline TURP & $\begin{array}{l}\text { Cutting loop } \\
\text { activation/ } \\
\text { detachment }\end{array}$ & Conversion to open & $\begin{array}{l}\text { Cautery automatically activated without surgeon use, } \\
\text { leading to intraperitoneal bladder perforation and } \\
\text { loop detachment }\end{array}$ & Not evaluated \\
\hline TURP & $\begin{array}{l}\text { Cutting loop } \\
\text { activation/ } \\
\text { detachment }\end{array}$ & Conversion to open & $\begin{array}{l}\text { Cautery activated itself without surgeon use, leading } \\
\text { to intraperitoneal bladder perforation and loop } \\
\text { detachment }\end{array}$ & Not evaluated \\
\hline TURP & $\begin{array}{l}\text { Cutting loop } \\
\text { activation/ } \\
\text { detachment }\end{array}$ & Conversion to open & $\begin{array}{l}\text { Cautery activated itself without surgeon use, leading } \\
\text { to intraperitoneal bladder perforation and loop } \\
\text { detachment }\end{array}$ & Not evaluated \\
\hline TURP & $\begin{array}{l}\text { Cutting loop } \\
\text { detachment }\end{array}$ & Urethral injury & Detachment of cutting loop caused urethral injury & Not evaluated \\
\hline TURP & $\begin{array}{l}\text { Cutting loop } \\
\text { detachment }\end{array}$ & Urethral injury & Detachment of cutting loop caused urethral injury & Not evaluated \\
\hline TURP & $\begin{array}{l}\text { Resectoscope } \\
\text { detachment }\end{array}$ & Conversion to open & $\begin{array}{l}\text { Unable to retrieve detached tip, intraperitoneal } \\
\text { bladder perforation encountered while attempting to } \\
\text { remove tip }\end{array}$ & Misuse by user \\
\hline TURP & $\begin{array}{l}\text { Electrosurgical } \\
\text { generator }\end{array}$ & $\begin{array}{l}\text { Cutaneous burns } \\
\text { (urethral meatus) }\end{array}$ & $\begin{array}{l}\text { Device evaluated by manufacturer and found to be in } \\
\text { good working condition. }\end{array}$ & Unknown \\
\hline TURP & $\begin{array}{l}\text { Electrosurgical } \\
\text { generator }\end{array}$ & $\begin{array}{l}\text { Cutaneous burns } \\
\text { (urethral meatus) }\end{array}$ & $\begin{array}{l}\text { Manufacturer review demonstrated an increased } \\
\text { leakage current for the generator due to defective } \\
\text { uninterruptible power supply }\end{array}$ & $\begin{array}{l}\text { Manufacturer } \\
\text { defect }\end{array}$ \\
\hline TURP & $\begin{array}{l}\text { Electrosurgical } \\
\text { generator }\end{array}$ & $\begin{array}{l}\text { Cutaneous burns } \\
\text { (urethral meatus) }\end{array}$ & $\begin{array}{l}\text { Device evaluated by manufacturer and found to be in } \\
\text { good working condition. }\end{array}$ & Unknown \\
\hline HoLEP & $\begin{array}{l}\text { Morcellator } \\
\text { dysfunction }\end{array}$ & Hemorrhage & $\begin{array}{l}\text { Difficulty with morcellation and bladder perforation } \\
\text { that required blood transfusion }\end{array}$ & $\begin{array}{l}\text { Manufacturer } \\
\text { defect }\end{array}$ \\
\hline HoLEP & $\begin{array}{l}\text { Morcellator } \\
\text { dysfunction }\end{array}$ & Conversion to open & $\begin{array}{l}\text { Difficulty with morcellating tissue and resulting } \\
\text { intraperitoneal bladder perforation requiring open } \\
\text { repair }\end{array}$ & $\begin{array}{l}\text { Manufacturer } \\
\text { defect }\end{array}$ \\
\hline HoLEP & $\begin{array}{l}\text { Morcellator } \\
\text { dysfunction }\end{array}$ & Conversion to open & $\begin{array}{l}\text { Unable to morcellate tissue, required conversion to } \\
\text { open to remove adenoma }\end{array}$ & Not evaluated \\
\hline HoLEP & $\begin{array}{l}\text { Morcellator } \\
\text { dysfunction }\end{array}$ & Conversion to open & $\begin{array}{l}\text { Unable to morcellate tissue, required conversion to } \\
\text { open to remove adenoma }\end{array}$ & Not evaluated \\
\hline HoLEP & $\begin{array}{l}\text { Morcellator } \\
\text { dysfunction }\end{array}$ & ICU admission & $\begin{array}{l}\text { Difficulty with morcellation and bladder perforation } \\
\text { that required ICU stay }\end{array}$ & $\begin{array}{l}\text { Manufacturer } \\
\text { defect }\end{array}$ \\
\hline GreenLight $^{\mathrm{TM}}$ & $\begin{array}{l}\text { End-firing } \\
\text { laser fiber }\end{array}$ & $\begin{array}{l}\text { Extraperitoneal } \\
\text { bladder } \\
\text { perforation }\end{array}$ & $\begin{array}{l}\text { Excessive heat accumulation causing bladder } \\
\text { perforation }\end{array}$ & Misuse by user \\
\hline GreenLight $^{\mathrm{TM}}$ & $\begin{array}{l}\text { End-firing } \\
\quad \text { laser fiber }\end{array}$ & $\begin{array}{l}\text { Extraperitoneal } \\
\text { bladder } \\
\text { perforation }\end{array}$ & $\begin{array}{l}\text { Excessive heat accumulation causing bladder } \\
\text { perforation }\end{array}$ & Misuse by user \\
\hline UroLift $^{\circledR}$ & $\begin{array}{l}\text { Needle } \\
\text { breakage }\end{array}$ & Second procedure & $\begin{array}{l}\text { Needle broke off during device use, required second } \\
\text { procedure to remove when recognized }\end{array}$ & Misuse by user \\
\hline UroLift $^{\circledR}$ & $\begin{array}{l}\text { Needle } \\
\text { breakage }\end{array}$ & Hemorrhage & $\begin{array}{l}\text { Needle broke off during device use, patient had } \\
\text { significant bleeding that required blood transfusion }\end{array}$ & Not evaluated \\
\hline
\end{tabular}


Table 6. MAUdE-Level Stratification of Individual Devices

\begin{tabular}{lclll}
\hline & MAUDE I & MAUDE II & MAUDE III & MAUDE IV \\
\hline TURP & $21(10.7 \%)$ & $0(0 \%)$ & $0(0 \%)$ & $0(0 \%)$ \\
$\quad$ Energy cable & $45(22.8 \%)$ & $0(0 \%)$ & $1(0.5 \%)$ & $0(0 \%)$ \\
$\quad$ Resectoscope & $111(56.3 \%)$ & $2(1.0 \%)$ & $3(1.5 \%)$ & $0(0 \%)$ \\
$\quad$ Cutting loop & $11(5.6 \%)$ & $3(1.5 \%)$ & $0(0 \%)$ & $0(0 \%)$ \\
$\quad$ Electrical generator & $13(33.3 \%)$ & $0(0 \%)$ & $0(0 \%)$ & $0(0 \%)$ \\
$\begin{array}{l}\text { HoLEP } \\
\text { Laser fiber }\end{array}$ & $18(46.1 \%)$ & $1(2.6 \%)$ & $3(7.7 \%)$ & $1(2.6 \%)$ \\
$\quad$ Morcellator & $3(7.7 \%)$ & $0(0 \%)$ & $0(0 \%)$ & $0(0 \%)$ \\
$\quad$ Endoscope & $14(87.5 \%)$ & $1(6.3 \%)$ & $1(6.3 \%)$ & $0(0 \%)$ \\
$\begin{array}{l}\text { UroLift } \\
\quad \text { UroLift }\end{array}$ & implant & $2(0.1 \%)$ & $0(0 \%)$ & $0(0 \%)$ \\
$\begin{array}{l}\text { GreenLight } \\
\text { Laser fiber }\end{array}$ & $2313(99.9 \%)$ & & & \\
\hline
\end{tabular}

urologists have a plethora of tools in their arsenal to combat BPH. When the indication is clear with regard to anticoagulation or preservation of ejaculatory function, then a specific modality is preferred such as GreenLight ${ }^{\mathrm{TM}}$ and UroLift $^{\circledR}$, respectively. We sought to investigate if any device-related malfunctions and complications were present that could help clinicians select a device with a higher safety profile.

GreenLight $^{\mathrm{TM}}$ showed an improved safety profile compared with other device modalities when examined as a whole. However, this finding should be interpreted cautiously given the OR of 0.01 and that the exact prevalence of GreenLight ${ }^{\mathrm{TM}}$ cases performed annually is not represented in the database. Given the high number of GreenLight ${ }^{\mathrm{TM}}$ reports compared with the other devices, we also performed a subset analysis to control for any skewing in favor of GreenLight ${ }^{\mathrm{TM}}$ data. When modalities were compared without the GreenLight $^{\mathrm{TM}}$ data, no statistically significant relationship could be demonstrated when comparing level I vs level II-IV malfunctions. Overall, our findings suggest that contemporary $\mathrm{BPH}$ treatment modalities are safe and associated with minimal harm to the patient. Selection of device should rely upon the comfort level and familiarity of the practitioner. In certain cases, consideration may be given to the GreenLight ${ }^{\mathrm{TM}}$ laser for its safety profile.

GreenLight ${ }^{\mathrm{TM}}$ laser appeared to be associated with a higher proportion of device malfunction reports compared with the other modalities (2315 vs 252 reports, respectively). Various studies have shown that there is not only an increase in the use of laser therapy for BPH but also a higher proportion of patients had GreenLight ${ }^{\mathrm{TM}}$ vs TURP in randomized control trials. ${ }^{3,11-14}$ Furthermore, GreenLight ${ }^{\mathrm{TM}}$ laser therapy is often a device rental with the surgical representative available at the time of surgery. A dedicated representative has an increased knowledge of the device and is more likely to report malfunctions than hospital staff who may not be familiar with the equipment. This allows for a more standardized reporting system when a device malfunction occurs, as opposed to the use of TURP or HoLEP where a malfunction or complication may only be documented in MAUDE at the user discretion level. Although a high number of GreenLight ${ }^{\mathrm{TM}}$ cases were recorded, the total denominator of devices in the MAUDE database is not available. GreenLight ${ }^{\mathrm{TM}}$ showed an improved safety profile on overall analysis, with the other devices showing an increased risk. We attribute this difference to a skew in favor of GreenLight ${ }^{\mathrm{TM}}$ as the total number of devices was higher by 10 -fold. Our subset analysis shows that all the devices are generally safe as there was no statistically significant risk associated with TURP, HoLEP, or UroLift and that GreenLight ${ }^{\mathrm{TM}}$ is safe with minimal complications to the patient. Overall, the devices on a whole were $99 \%$ safe with regard to any malfunction that occurred. As described above, the rate of user-dependent malfunction, after device interrogation, was over $40 \%$.

Given the high number of malfunctions attributed to the user, this serves as a targetable area in training that can be corrected with proper management of each device and understanding indications for its use. As new technology is developed, both surgeons in training and in practice should actively work with device manufacturers in understanding how to properly use new technology and help our patients. Ultimately, it is the clinician's responsibility to select a modality that can provide the best results and minimize any potential harm to the patient.

Despite patients having complications, $44.4 \%$ of the devices were not evaluated. The device that was associated with the most harm and a significant complication was the morcellator used during HoLEP. Although no death was reported, dysfunction or improper working of the morcellator led to the most conversions to open, an ICU admission, and also hemorrhage. The use of morcellation in gynecology as presented from the MAUDE database has been associated with pelvic infection, postoperative bleeding, bowel injury, ICU admission, hysterectomy, and death. ${ }^{15}$ Data regarding complications of this device in urology are limited; however, the bipolar loop has been shown as an alternative to feasibly resect the tissue when the morcellator is unable to, preventing conversion to open because of an intraperitoneal bladder injury or removal of the tissue. ${ }^{16}$

Three cases of cutaneous burns to the urethra are also highlighted during use of TURP, but these were found to be related to a defective electrosurgical generator. These complications likely could have been avoided with updated and proper working equipment. At our institution, we perform a quinquennial review of all surgical devices for repairs and 
replacement in addition to when the equipment malfunctions or breaks on an as-needed basis. Our review generally results in the identification of $20 \%$ to $30 \%$ of our reusable equipment that is either sent for repairs or replaced. We feel this is one method to control or reduce any possible complications that can occur from equipment that an institution owns. Further discussion with manufacturers to understand proper housekeeping and an appropriate time interval for such review should be determined by each institution and surgical center.

Multiple subdisciplines of urology, including endourology, minimally invasive surgery/oncology, and female urology, have commonly used devices such as ureteroscopes, lasers, percutaneous nephrolithotomy (PCNL) instruments, robotic instruments, mesh, and InterStim ${ }^{\mathrm{TM}}$ implants that have had malfunctions and subsequent complications reported. ${ }^{5,6,17-19}$ The use of a classification system has been highlighted with robotic, PCNL, and now BPH surgery complications. The MAUDE database has the potential to present findings that would otherwise be unknown if there was no anonymous reporting system. Adoption of the MAUDE classification system as a metric by reporters will provide more objective reporting options and also help improve the quality of the FDA database.

Several limitations of our study must be acknowledged. The MAUDE database consists of voluntary and involuntary self-reporting, which is not regulated or standardized. Therefore, variability in data is common especially with the reporting of the particular malfunction or complication. Furthermore, the exact process for a device to be reviewed is unclear, but physicians, nurses, and facility administrators have submitted the reports. This can create ambiguity as the majority of these individuals may not be familiar with the case or device. The manufacturer review process and what quantifies a device as misuse by the user are not described in the database. Additionally, there are no data available about the prevalence of each specific case and, as a result, we do not know the total number of those cases. This prevents any longitudinal understanding of the frequency or incidence of each particular event or complication. As no patient identifiable information is present, there is no possibility of understanding patient demographics such as age, race, obesity, socioeconomic status, hospital setting, or prognosis of the patient. Conversely, the same is true of the surgeon and lack of understanding for the particular case mix index/case complexity, case volume, overall experience, or fellowship training. We recommend a joint collaboration between surgical staff, physicians, and surgical representatives to report all significant device defects and cases where a complication has occurred to gain further understanding of all types of device complications, increase user/manufacturer awareness, and ultimately reduce harm to our patients.

\section{Conclusion}

Our findings demonstrate the spectrum of device-related malfunctions that can occur during various BPH surgeries. By incorporating a classification system, we were able to standardize the device-related complications for these tools and our methods can be applied to any surgical device or instrument. These findings are useful for benchmarking outcomes, improving surgical performance, and patient counseling and can be of use in future quality improvement studies. We found that all BPH devices were over $99 \%$ safe when a malfunction occurred and that clinicians should use the modality they are most comfortable with as over $40 \%$ of the malfunctions are user related. Additionally, an improved safety profile is seen with the use of GreenLight ${ }^{\mathrm{TM}}$ laser therapy and consideration to this technique should be given for appropriate situations. Of note, great care should be taken during the use of the morcellator during HoLEP as it was found to have the greatest number of higher grade complications, but this was not significant. Our findings highlight the safety of BPH surgery as well as the importance of training urologists in proper operation and management of these devices to maximize surgical efficiency and decrease patient harm.

\section{Author Disclosure Statement}

No competing financial interests exist.

\section{References}

1. Auffenberg GB, Helfand BT, McVary KT. Established medical therapy for benign prostatic hyperplasia. Urol Clin North Am 2009;36:443-459, v-vi.

2. Barry MJ, Fowler FJ, Jr., Bin L, Pitts JC, 3rd, Harris CJ, Mulley AG, Jr. The natural history of patients with benign prostatic hyperplasia as diagnosed by North American urologists. J Urol 1997;157:10-14; discussion 14-15.

3. Patel ND, Parsons JK. Epidemiology and etiology of benign prostatic hyperplasia and bladder outlet obstruction. Indian J Urol 2014;30:170-176.

4. Nunes RLV, Antunes AA, Constantin DS. Contemporary surgical treatment of benign prostatic hyperplasia. Rev Assoc Med Bras (1992) 2017;63:711-716.

5. Gupta P, Schomburg J, Krishna S, et al. Development of a classification scheme for examining adverse events associated with medical devices, specifically the DaVinci surgical system as reported in the FDA MAUDE database. J Endourol 2017;31:27-31.

6. Patel NH, Schulman AA, Bloom JB, et al. Device-related adverse events during percutaneous nephrolithotomy: Review of the manufacturer and user facility device experience database. J Endourol 2017;31:1007-1011.

7. Gupta NP, Nayyar R. Management of large prostatic adenoma: Lasers versus bipolar transurethral resection of prostate. Indian J Urol 2013;29:225-235.

8. Jhanwar A, Sinha RJ, Bansal A, Prakash G, Singh $\mathrm{K}$, Singh V. Outcomes of transurethral resection and holmium laser enucleation in more than $60 \mathrm{~g}$ of prostate: A prospective randomized study. Urol Ann 2017;9: 45-50.

9. Piotrowicz G, Syrylo T, Jedynak R, Zielinski H. Efficacy and safety of photoselective vaporization of the prostate with $120 \mathrm{~W} 532 \mathrm{~nm}$ laser in patients with benign prostatic hyperplasia on anticoagulation or antiplatelet therapy: Observations on long-term outcomes. Photomed Laser Surg 2018;36:273-283.

10. Gratzke C, Barber N, Speakman MJ, et al. Prostatic urethral lift vs transurethral resection of the prostate: 2-year results of the BPH6 prospective, multicentre, randomized study. BJU Int 2017;119:767-775.

11. Ding H, Du W, Lu ZP, Zhai ZX, Wang HZ, Wang ZP. Photoselective green-light laser vaporisation vs. 
TURP for BPH: Meta-analysis. Asian J Androl 2012;14: 720-725.

12. Lowrance WT, Southwick A, Maschino AC, Sandhu JS. Contemporary practice patterns of endoscopic surgical management for benign prostatic hyperplasia among urologists in the United States. J Urol 2013;189:18111816.

13. Whelan JP, Bowen JM, Burke N, et al. A prospective trial of GreenLight PVP (HPS120) versus transurethral resection of the prostate in the treatment of lower urinary tract symptoms in Ontario, Canada. Can Urol Assoc J 2013;7: 335-341.

14. Malaeb BS, Yu X, McBean AM, Elliott SP. National trends in surgical therapy for benign prostatic hyperplasia in the United States (2000-2008). Urology 2012;79:1111-1116.

15. Haber K, Hawkins E, Levie M, Chudnoff S. Hysteroscopic morcellation: Review of the manufacturer and user facility device experience (MAUDE) database. J Minim Invasive Gynecol 2015;22:110-114.

16. Shinojima T, Yoshimine S. Difficulty in the intravesical morcellation procedure for leiomyoma of the prostate enucleated by HoLEP. BMJ Case Rep 2013;2013. DOI: 10.1136/bcr-2013-200200.

17. Shah HN, Badlani GH. Mesh complications in female pelvic floor reconstructive surgery and their management: A systematic review. Indian J Urol 2012;28:129-153.

18. Sterling ME, Hartigan SM, Wein AJ, Smith AL. A standardized surgical technique for removal of the Interstim tined lead. Can J Urol 2016;23:8471-8475.
19. Tanimoto R, Cleary RC, Bagley DH, Hubosky SG. Ureteral avulsion associated with ureteroscopy: Insights from the MAUDE database. J Endourol 2016;30:257-261.

Address correspondence to: Neel H. Patel, MD

Department of Urology New York Medical College 40 Sunshine Cottage Road Skyline $1 S-B 50$ Valhalla, NY 10595

E-mail: neel.pate12@wmchealth.org

$\begin{aligned} & \text { Abbreviations Used } \\ & \mathrm{BPH}=\text { benign prostatic hyperplasia } \\ & \mathrm{CI}=\text { confidence interval } \\ & \mathrm{FDA}=\text { Food and Drug Administration } \\ & \mathrm{HoLEP}=\text { holmium laser enucleation of the prostate } \\ & \mathrm{IPSS}=\text { International Prostate Symptom Score } \\ & \mathrm{MAUDE}=\text { Manufacturer and User Facility Device } \\ & \mathrm{PCNL}=\text { experience } \\ & \mathrm{OR}=\text { odds ratio } \\ & Q_{\mathrm{max}}=\text { urinary flow rates } \\ & \mathrm{TURP}=\text { transurethral resection of the prostate }\end{aligned}$

